\title{
Medievalista
}

Online

$29 \mid 2021$

Número 29

\section{Virtual International Medieval Congress (vIMC), University of Leeds -6 a 10 de Julho de 2020}

Virtual International Medieval Congress (vIMC), University of Leeds - 6th to 10th of July 2020

Diana Martins and Maria João Branco

\section{OpenEdition}

\section{Journals}

Electronic version

URL: https://journals.openedition.org/medievalista/4016

DOI: 10.4000/medievalista.4016

ISSN: $1646-740 X$

\section{Publisher}

Instituto de Estudos Medievais - FCSH-UNL

Printed version

Number of pages: 419-424

\section{Electronic reference}

Diana Martins and Maria João Branco, "Virtual International Medieval Congress (vIMC), University of Leeds - 6 a 10 de Julho de 2020", Medievalista [Online], 29 | 2021, Online since, connection on 12 June 2021. URL: http://journals.openedition.org/medievalista/4016 ; DOI: https://doi.org/10.4000/ medievalista.4016

This text was automatically generated on 12 June 2021.

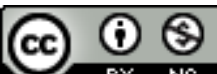

Mediavalista está licenciado com uma Licença Creative Commons - Atribuição-NãoComercial 4.0 Internacional. 


\section{Virtual International Medieval Congress (vIMC), University of Leeds -6 a 10 de Julho de 2020}

Virtual International Medieval Congress (vIMC), University of Leeds - 6th to 10th of July 2020

Diana Martins and Maria João Branco

\section{EDITOR'S NOTE}

Data recepção do artigo / Received for publication: 6 de Dezembro de 2020

1 O International Medieval Congress (IMC) de Leeds, que completou em 2019 vinte e cinco anos desde a sua primeira edição, é o maior Congresso Internacional do espaço europeu dedicado aos estudos medievais, reunindo anualmente medievalistas de todas as áreas científicas, que aí encontram um fórum de debate privilegiado. Importante, quer para os especialistas, quer para o público em geral interessado na Idade Média, este congresso costuma contar com cerca de 2700 participantes vindos de todo o mundo. Trata-se de um espaço privilegiado de trabalho, interacção, convívio, troca e amadurecimento de ideias, com sessões académicas, mesas redondas, encontros anuais de associações académicas e recepções oferecidas por editoras ou centros de investigação. $O$ programa académico é complementado por um programa social muito variado e por uma importante feira do livro medieval, com todas as grandes casas editoras e muitos alfarrabistas bem representados.

2 No atípico ano de 2020 continuou a ser tudo isso, embora de forma completamente diferente. Recorrendo às vantagens proporcionadas pelas novas tecnologias, a organização do Congresso, que em meados de Maio entendeu a impossibilidade de o realizar presencialmente, decidiu converter o Congresso e as suas atividades a um formato digital, no qual se tentou manter o mesmo dinamismo e diversidade de 
iniciativas de sempre. Assim, entre os dias 6 e 10 de Julho de 2020, no conforto e segurança das suas casas, investigadores e académicos beneficiaram deste grande Congresso e dos conteúdos transmitidos no mesmo. Nasceu, desta forma, o primeiro Virtual International Medieval Congress (vIMC), que manteve o tema originalmente previsto para 2020, Borders.

Duas conferências plenária ${ }^{1}, 528$ comunicações e mais de 3200 participantes originários de 60 países, que tiveram a possibilidade de se inscrever gratuitamente, conferiram a este evento um dinamismo muito particular e quer as comunicações, quer os debates decorreram de forma quase sem problemas. 0 evento virtual ultrapassou a dimensão de qualquer outro anterior e acabou por ser muito bem-sucedido (para os highlights do congresso, visitar https://www.imc.leeds.ac.uk/highlights-from-virtual-imc-2020/).

o Congresso concretizou-se através de um website e uma aplicação digital online do evento, disponível para computadores e dispositivos móveis, através dos quais se podia aceder ao programa, marcar numa agenda virtual as sessões de interesse e entrar nas diversas sessões ${ }^{2}$ e eventos digitais. Permitia igualmente navegar pelas promoções de algumas das mais importantes editoras internacionais que mantiveram, agora em modo virtual, as suas campanhas especiais para o período de decurso do congresso. Além disso, através da aplicação, era igualmente possível aceder às páginas individualmente criadas por cada um dos participantes no evento, uma ferramenta indispensável para o desenvolvimento das redes de contactos.

Como é habitual, o IEM participou no encontro científico. Tendo sido programadas originalmente seis sessões propostas pelo Instituto, a par com outras seis organizadas por outras instituições ou projetos de investigação, num total de 13 comunicações previstas por parte dos seus membros integrados, apenas uma foi concretizada, a de Diana Martins, que participou num painel sobre Travel, Trade and Negotiation com a comunicação intitulada "Crossing the Borders of Negotiation: Diplomatic Travel between Portugal and Aragon, 1300-1304", que teve cerca de 45 assistentes e uma excelente recepção.

6 O IEM esteve também presente no conjunto do que a organização apelidou de fringe events com uma drink's reception virtual, no decurso da qual se realizou uma relevante mesa redonda sobre o papel dos Centros de Estudos Medievais e da investigação sobre Idade Média na era pós-COVID19, e, sobretudo, sobre a relevância do medievalismo na emergência dos problemas actuais relacionados com a saúde pública, questões relacionadas com minorias étnico-religiosas, racismo e problemas ambientais. Participaram na mesa redonda, com comunicação, Axell Müller (director do IMC), Kurt Villads Jensen (Universidade de Estocolmo), Maria Soler Sala (em representação do IRCVM, Barcelona), Nahir Otaño García (University of New Mexico), Maria Pilar Lorenzo Gradín (em representação da Red de Estudios Medievales Interdisciplinares, Santiago de Compostela) e Simon Doubleday (Hofstra University, Nova Iorque). Discutiram-se as mudanças, impactos e inovações que a pandemia COVID19 acarretará consigo e como os estudos medievais podem beneficiar e fazer repensar as formas de investigação em curso. Um evento prolífico que permitiu não apenas discutir e analisar estratégias, mas também cativar jovens investigadores para colaborarem com o Instituto de Estudos Medievais.

7 Apesar de alguns problemas causados por trolls na plataforma, esta primeira experiência virtual à escala de um grande congresso constituiu um enorme sucesso, tendo sido possível realizar a maioria das sessões e comunicações sem sobressaltos. 
8 A facilidade de acesso à plataforma e a possibilidade de poder sair e entrar noutra sessão muito rapidamente foram, sem dúvida, duas das maiores vantagens deste novo formato. A entrada e saída rápida em sessões, por oposição à "correria" pelo campus de Leeds verificada em circunstâncias normais, possibilitou a cada um dos participantes usufruir mais comodamente das várias sessões do seu interesse e que ocorreram em paralelo, ao mesmo tempo que lhes possibilitou participar em mais do que um debate que estivesse em curso após cada sessão. Além disso, a redução do número de sessões paralelas, face ao que costuma ocorrer, permitiu que cada sessão tivesse uma assistência mais ampla e por essa razão uma discussão mais longa e diversa.

9 Para colmatar a falta de contacto presencial, a organização tentou reproduzir virtualmente os usuais momentos de confraternização do Congresso, proporcionando aos conferencistas um conjunto de eventos e convívios que tiveram lugar durante os dias em questão, nomeadamente, mesas redondas, virtual coffee meetings, apresentações e discussões de livros, visitas virtuais a sítios arqueológicos, workshops de escrita hebraica, medieval quizzes, narração de histórias, Q\&A com editoras como a Brepols e até a usual noite na discoteca, entre diversas outras iniciativas e actividades.

Em jeito de balanço final, e num evento desta dimensão e com tantos participantes, as vantagens não sucumbem perante as dificuldades. Muito pelo contrário. A possibilidade de contactar e discutir ideias com colegas interessados nos mesmos temas que nos leva à criação das indispensáveis networks, as quais hoje em dia, através do digital, permitem colmatar distâncias e apresentar, quer novas abordagens, quer resultados mais avançados, continua a constituir uma incontornável mais-valia do Congresso. $O$ uso de ferramentas como bases de dados, os SIG, digitalização de códices ou análises laboratoriais acabam também por permitir, muito à semelhança do open access, que mais pessoas tenham acesso a informação de forma mais livre e que consigam não apenas ganhar conhecimentos, mas também participar na construção dessas mesmas ferramentas. Outra importante vantagem deste evento, foi a abertura gratuita de inscrições que, embora não acessíveis a todos, permitiu a participação de muito mais delegados do que na versão presencial. Tudo isto evidencia que para se fazer um grande encontro de natureza científica é necessário sobretudo disponibilidade, vontade e saber procurar as ferramentas certas para que, mesmo em tempos em que é impossível viajar e a comunicação está limitada, as nossas ideias, dúvidas e propostas de resolução possam chegar a todos os interessados, por muito longe que estejam.

\section{NOTES}

1. A conferência inaugural "Perceived Boundaries: Managing Religious Diversity in Iberian Medieval Towns" foi apresentada pela reputada historiadora Ana Echevarría Arsuaga (Departamento de Historia Medieval y Ciencias y Téchnicas Historiográficas UNED), especialista no estudo das relações entre o Islão e o espaço ibérico medieval. A segunda conferência foi proferida por Hyunhee Park (Department of History, John Jay College of Criminal Justice, City University of New York), responsável por importantes 
trabalhos sobre a história global e intercâmbios culturais durante a Idade Média, que nos brindou com uma intervenção subordinada ao tema "Open Space and Flexible Borders - Theorizing Maritime Space Through Pre-Modern Sino-Islamic Connections”. Ambas as conferências, pela sua importância, foram disponibilizadas na página dedicada ao congresso: https://www.imc.leeds.ac.uk/imc-2020/vimc-2020-keynotelectures/.

2. Com recurso à plataforma de ensino online utilizada pela Universidade de Leeds, a Blackboard Collaborate Ultra.

\section{AUTHORS}

\section{DIANA MARTINS}

Universidade Nova de Lisboa, Faculdade de Ciências Sociais e Humanas, Instituto de Estudos Medievais. 1070-312 Lisboa, Portugal. dianawinnifriedmartins@gmail.com. https://orcid.org/ 0000-0002-6465-5191

\section{MARIA JOÃO BRANCO}

Universidade Nova de Lisboa, Faculdade de Ciências Sociais e Humanas, Instituto de Estudos Medievais. 1070-312 Lisboa, Portugal. mjbranco@fcsh.unl.pt. https://orcid.org/ 0000-0002-7165-5958 